\title{
Proposed criteria for schizophrenia remission
}

This article was published in the following Dove Press journal:

Neuropsychiatric Disease and Treatment

16 April 2014

Number of times this article has been viewed

\section{Bandar AlAqeel \\ Department of Psychiatry, University of Toronto, Toronto, ON, Canada}

Correspondence: Bandar AlAqeel Ontario Shores Centre for Mental Health Sciences, 700 Gordon St, Whitby, ON, LIN 5S9, Canada

Email bandar.alaqeel@mail.utoronto.ca

\section{Dear editor}

I read with interest the article recently published in Neuropsychiatric Disease and Treatment, titled, "Design and validation of standardized clinical and functional remission criteria in schizophrenia" by Mosolov et al. ${ }^{1}$ I have a few comments here about the design and reporting of their study. First, in their introduction the authors stated, "Dividing remission into partial and complete, based on residual symptoms using the Diagnostic and Statistical Manual of Mental Disorders, 4th Edition (DSM-IV)[...] and the International Classification of Diseases Version (ICD10)[...], is subjective and does not give an indication of the benefits of treatment or a level of success. Outcome can be defined along dimensional and categorical lines." I disagree with this statement, as the evidence has accumulated supporting the validity of the Remission in Schizophrenia Working Group (RSWG) criteria, which was devised by Andreasen et al. ${ }^{2}$ Moreover, these criteria utilized dimensional symptoms directly from DSM criteria and have been validated for clinical use by many studies. ${ }^{3-5}$ Second, the methodology section was filled with unnecessary details about each group of participants that - in my opinion - could be combined and summarized. Third, it seems that on many occasions the authors had only utilized the cross-sectional aspect of the RSWG criteria and ignored the duration in their analysis; we have discouraged against such practice in our report, ${ }^{6}$ as this is one of the reasons for drawing erroneous conclusions about the RSWG criteria. Fourth, Mosolov et $\mathrm{al}^{1}$ in their analysis have not specified if they performed a power analysis before commencing on the data analysis. Reporting the power analysis should be a part of good reporting. Fifth, they utilized data from different studies without giving a short description of the source study. Sixth, the investigators reported that $65.5 \%$ of patients corresponded to (met) the new the Standardized Clinical and Functional Remission Criteria (SCFRC). This percentage seems very high and not in line with previous studies, ${ }^{6}$ and the authors failed to explain such discrepancy in their findings. Seventh, the authors reported that they utilized a dimensional approach to reach their criteria. However, they used non-contemporary classification and old criteria to derive their own in a way that makes it confusing to apply for future researchers and clinicians. Eighth, the frequency of the participants' assessment - to ensure remission attainment - was not clearly elucidated. It has been shown that patients are moving-in-and-out of remission, ${ }^{7}$ and it is possible that due to infrequent assessment the remission status (or non-remission) was not adequately recognized. Lastly, the investigators were not clear on the difference between naturalistic and controlled trials, as they wrote, "we performed 
a naturalistic, controlled trial of modern versus routine therapeutic approaches." Naturalistic and controlled trials are totally different entities in research methodology, so the study could be either naturalistic, ie, without the investigators intervention, or a controlled trial where the treatment intervention is under the control of the investigators. ${ }^{8}$

\section{Disclosure}

The author reports no conflicts of interest in this communication.

\section{References}

1. Mosolov SN, Potapov AV, Ushakov UV, Shafarenko AA, Kostyukova AB. Design and validation of standardized clinical and functional remission criteria in schizophrenia. Neuropsychiatr Dis Treat. 2014;10:167-181.

2. Andreasen NC, Carpenter WT Jr, Kane JM, Lasser RA, Marder SR, Weinberger DR. Remission in schizophrenia: proposed criteria and rationale for consensus. Am J Psychiatry. 2005;162(3):441-449.
3. Opler MG, Yang LH, Caleo S, Alberti P. Statistical validation of the criteria for symptom remission in schizophrenia: preliminary findings. BMC Psychiatry 2007;7:35.

4. Wunderink L, Nienhuis FJ, Sytema S, Wiersma D. Predictive validity of proposed remission criteria in first-episode schizophrenic patients responding to antipsychotics. Schizophr Bull. 2007;33(3): 792-796.

5. Dunayevich E, Sethuraman G, Enerson M, Taylor CC, Lin D. Characteristics of two alternative schizophrenia remission definitions: relationship to clinical and quality of life outcomes. Schizophr Res. 2006;86(1):300-308.

6. AlAqeel B, Margolese HC. Remission in schizophrenia: critical and systematic review. Harv Rev Psychiatry. 2012;20(6):281-297.

7. Boter H, Peuskens J, Libiger J, et al; EUFEST study group. Effectiveness of antipsychotics in first-episode schizophrenia and schizophreniform disorder on response and remission: an open randomized clinical trial (EUFEST). Schizophr Res. 2009;115(2-3):97-103.

8. Helmchen H. Ethical issues in naturalistic versus controlled trials. Dialogues Clin Neurosci. 2011;13(2):173-182. 


\section{Authors' reply: are we really satisfied now with the Remission in Schizophrenia Working Group criteria?}

\author{
Sergey N Mosolov \\ Andrey $V$ Potapov \\ Moscow Research Institute of Psychiatry, Moscow, Russia
}

Correspondence: Sergey N Mosolov

Moscow Research Institute of Psychiatry, 3 Poteshnaya ul,

107076 Moscow, Russia

Tel +7 4959633777

Fax +7 4959631002

Email profmosolov@mtu-net.ru

\section{Dear editor}

We thank Dr AlAqeel for the interest and valuable feedback on our article "Design and validation of standardized clinical and functional remission criteria in schizophrenia." It is a great pleasure and additional opportunity for us to discuss the limitations of our work and the validity of the obtained results, as well as some general aspects of this actual topic. We are very well aware of the methodological shortcomings of our study as were noted at the bottom of discussion section. Let us give you point by point answers to each critical comment and try to present our explanation as best as possible.

i. The Remission in Schizophrenia Working Group (RSWG) criteria, ${ }^{2}$ despite validation within the framework of naturalistic or intervention studies, only covers a minor part of schizophrenia outpatients (about one third), including patients with stable, long-term symptomatology as was correctly mentioned in your highquality review, ${ }^{3}$ and was also shown in the introduction to our article..$^{4-14}$ In other words, it could be interpreted that $70 \%$ of schizophrenia outpatients are out of remission and maintain some level of exacerbation. This is against common sense and clinical reality. Moreover, the RSWG criteria are not included in any national or international classifications and, as a consequence, are out of everyday clinical practice. Yes, the RSWG criteria are based on a three-dimensional model of schizophrenia that comprises positive, disorganised, and negative dimensions. However, this model does not include such important dimensions as affective symptoms, cognitive impairment, insight, personality changes, quality of life, and level of functioning. In remission, all these symptoms and aspects are important, because it is very difficult to speak about remission when, for example, the patient has severe postpsychotic depresssion and a very low functioning level, but achieved a 3-point level on the RSWG symptomatic criteria. This also holds true for cognitive deficit or change of personality, especially concerning fine volitional impairments in Verschroben-like changes. Therefore, the RSWG criteria are closer to sustained treatment response than to functional remission or recovery, and that is why they are so often exploited in clinical trials. However, the biopsychosocial approach and the reality of clinical practice dictate more complex and personalized evaluation of remission state.

ii. It seemed very important for us and for some of our independent reviewers to give the full clinical characteristic of our different samples, because we used some older phenomenological notions less used by our Western colleagues; we were even urged to give an additional glossary for better understanding. Still, we think that it is very useful to validate the conversion of this longstanding empirical experience and euristic clinical approach to operational criteria, since it provides a more or less reliable prognosis of individual outcome. We also gave a comprehensive description of participants, especially their diagnoses by the ICD-10 (International Classification of Diseases Version 10), because in our opinion the level of possible symptom reduction and readjustment of functioning depends on clinical course and type of schizophrenia, and that is the reason why the Standardized Clinical and Functional Remission Criteria (SCFRC) have been stratified by the ICD-10 diagnostic subtypes. In recent classifications (Diagnostic and Statistical Manual of Mental Disorders, 5th Edition [DSM-5] and ICD-11 project) this Kraepelinian typology was converted to dimensions (specifiers), and we fully agree with this approach. Essentially, we included most of these specifiers in SCFRC.

iii. We validated the RSWG criteria in a Russian schizophrenia patient population using both the symptomatic and duration criteria in the observational study ${ }^{9,15}$ and in the interventional trial ${ }^{16,17}$ separately from the SCFRC. The study presented in the current article was planned as exploratory and descriptive in nature, so we used a cross-sectional design to obtain pivotal results for further research.

iv. The data for our article were based on the re-analyses of our clinical studies as well as an exploratory cross-sectional study, and the reason for this was to get quick results, which could guide us to start 
the validation process and help to carefully design well-powered, confirmatory studies. Our preliminary, naturalistic study was not statistically powered at all, as it was limited by the two city care areas, lack of manpower, and other necessary resources. Therefore, this article reflects the exploratory stage of the SCFRC validation process and we are very appreciative of $\mathrm{Dr}$ AlAqeel's feedback on our attempts.

v. It is true that for the preliminary validation of the SCFRC we used different independent studies, but in every instance we have tried to indicate the source study. That also formed part of the reason for our detailed sample characteristic. Full information on all our studies can be found in our earlier publications. ${ }^{9,15-17}$

vi. The previous studies which Dr AlAqeel mentions used the RSWG criteria, whereas we reported this result for the SCFRC. Our results highlight the differences between the RSWG criteria and the SCFRC, and consider the possibility of achieving remission in less favorable chronic patients with marked residual but stable symptomatology.

vii. We are really disappointed and mostly disagree with this comment because our objective was quite the opposite: namely, it was an attempt to combine the categorical and dimensional approaches for a better individual outcome prognosis. We tried to present the new criteria in a very simple, operational way using well-known validated scales like PANSS (Positive and Negative Syndrome Scale) and PSP (Personal and Social Performance) for dimensions (disorganization, affective, positive and negative symptoms, functioning, etc). Obviously this is now a mainstream of the up-to-date diagnostic systems like DSM-5 or ICD-11. The SCFRC was developed on the ICD-10 basis for two reasons: 1) this classification is the only one in use in clinical practice in the Russian Federation, and we were interested in supplying a practical, useful instrument for the diagnostic of remission as well as to attract doctors' attention to frequently unrecognized symptomatology in remission period (affective symptoms, lack of insight, change of personality, and impairments in cognition and in different areas of functioning); and 2) the ICD-10, in our opinion, better reflects clinical courses of schizophrenia than the DSM-IV. Analyzing symptomatology - which is important in the remission period but missed in the three-dimensional model - and converting it to the dimensional items of the well-validated PANSS, we developed the SCFRC. Generally, we agree with RSWG that eight core symptoms and a 3-point cut-off level are good targets for the treatment and can be useful for patient motivation, but this is not a currently achievable goal for the majority of schizophrenia patients with stable, long-term residual symptoms. That is why we consider the SCFRC as an add-in for the RSWG criteria in unfavorable courses of schizophrenia. SCFRC must be adapted to classifications other than the ICD-10. Moreover, we think that the most of the dimensions from the new DSM-5 and from the ICD-11 project could be rationally incorporated into the SCFRC instead of former clinical subtypes.

viii. In the observational study we followed the pattern of clinical practice and assessed patients on their regular visits to outpatient services (approximately monthly); in the interventional study participants were assessed on screening visit, and weeks $5,9,13,25,37$, and 53 of the treatment. More details can be found in our previous publications. ${ }^{9,15-17}$ If a patient during 6 consecutive months on one of the visits does not meet the symptomatic remission criteria, the duration criterion was considered as having been failed. We strongly support the conclusion of your recent review ${ }^{3}$ that in many cases symptom severity may fluctuate, and a 6-month period is not sufficient to assess remission correctly. To obtain more consistent and reliable results it would be wise to increase the duration criterion to 1 year, with at least bimonthly symptom evaluations.

ix. We fully agree with your last comment that naturalistic and controlled studies have different methodology, and you are correct to indicate our misprint, because we meant non-interventional trial as defined by DIRECTIVE 2001/20/EC. When we wrote "naturalistic, controlled trial" we just meant naturalistically "controlled" in the sense that there were two naturalistically-formed therapeutic groups of comparison, and the group of routine therapy was often formally named as "control.". More details about this observational study are found in our previous publication. ${ }^{15}$

To conclude, we are very grateful to Dr AlAqeel for raising important issues regarding the methodology pitfalls of our study and the problem of future development of the universally accepted definition of remission in schizophrenia. We are open to further discussion and collaboration on this really hot topic that is in high demand in clinical practice. 


\section{Disclosure}

The authors report no conflicts of interest in this communication.

\section{References}

1. Mosolov SN, Potapov AV, Ushakov UV, Shafarenko AA, Kostyukova AB. Design and validation of standardized clinical and functional remission criteria in schizophrenia. Neuropsychiatr Dis Treat. 2014;10:167-181.

2. Andreasen NC, Carpenter WT Jr, Kane JM, Lasser RA, Marder SR, Weinberger DR. Remission in schizophrenia: proposed criteria and rationale for consensus. Am J Psychiatry. 2005;162(3):441-449.

3. AlAqeel B, Margolese HC. Remission in schizophrenia: critical and systematic review. Harv Rev Psychiatry. 2012;20(6):281-297.

4. Lasser RA, Bossie CA, Gharabawi GM, Kane JM. Remision in schizophrenia: Results from a 1-year study of long-acting risperidone injection. Schizophr Res. 2005;77(2-3):215-227.

5. Helldin L, Kane JM, Karilampi U, Norlander T, Archer T. Remission and cognitive ability in a cohort of patients with schizophrenia. J Psychiatr Res. 2006;40(8):738-745.

6. De Hert M, van Winkel R, Wampers M, Kane J, van Os J, Peuskens J. Remission criteria for schizophrenia: evaluation in a large naturalistic cohort. Schizophr. Res. 2007;92:68-73.

7. San L, Ciudad A, Alvarez E, Bobes J, Gilaberte I. Symptomatic remission and social/vocational functioning in outpatients with schizophrenia: prevalence and associations in a cross-sectional study. Eur Psychiatry. 2007;22(8):490-498.

8. Wunderink L, Sytema S, Nienhuis FJ, Wiersma D. Clinical recovery in first-episode psychosis. Schizophr Bull. 2009;35(2):362-369.

9. Mosolov SN, Potapov AV, Dediurina IuM, Ushakov IuV, Tsukarzi EE. [The validation of international criteria for remission in schizophrenia in the outpatient population]. Zh Nevrol Psikhiatr Im S S Korsakova. 2010;110(5 Pt 1):71-75. Russian.
10. Li CT, Su TP, Chou YH, et al. Symptomatic resolution among Chinese patients with schizophrenia and associated factors. J Formos Med Assoc. 2010;109(5):378-388.

11. Wolter A, Preuss UW, Krischke NR, Wong WM, Zimmermann J. Remission, prediction and stability of symptoms in schizophrenia: A naturalistic 12-month follow-up study. Int J Psychiatry Clin Pract. 2010;14(3):160-167.

12. Kurihara T, Kato M, Reverger R, Tirta IG. Remission in schizophrenia: a community- based 6-year follow-up study in Bali. Psychiatry Clin Neurosci. 2011;65:476-482.

13. Zimmermann J, Wolter A, Krischke NR, Preuss UW, Wobrock T, Falkai P. [Response and remission in schizophrenic subjects]. Nervenarzt. 2011;82(11):1440-1448. German [with English abstract].

14. Levine SZ, Rabinowitz J, Ascher-Svanum H, Faries DE, Lawson AH. Extent of attaining and maintaining symptom remission by antipsychotic medication in the treatment of chronic schizophrenia: evidence from the CATIE study. Schizophr Res. 2011;133(1-3):42-46.

15. Mosolov SN, Potapov AV, Ushakov UV. Remission in schizophrenia: results of cross-sectional with 6-month follow-up period and 1-year observational therapeutic studies in an outpatient population. Ann Gen Psychiatry. 2012;11(1):1.

16. Potapov AV, Tsukarzi EE, Mosolov SN. Response, Remission and Relapse during the long-term treatment of schizophrenia patients with long-acting injectable risperidone versus olanzapine. In: Abstracts from the XXVI CINP Congress, Munich, July 13-17, 2008. Intern Jour Neuropsychopharmacology. 2008;11(Suppl S1):158.

17. Mosolov SN, Tsukarzi EE, Potapov AV. Comparative efficacy, tolerability and influence on social functioning of risperidone prolong (Consta) and olanzapine during the long-term treatment of schizophrenia and schizoaffective disorder (randomized controlled study). Sovremennaya Terapia Psikhicheskyh Rasstroistv. 2008;2:10-18. Russian [with English abstract].
Neuropsychiatric Disease and Treatment

\section{Publish your work in this journal}

Neuropsychiatric Disease and Treatment is an international, peerreviewed journal of clinical therapeutics and pharmacology focusing on concise rapid reporting of clinical or pre-clinical studies on a range of neuropsychiatric and neurological disorders. This journa is indexed on PubMed Central, the 'PsycINFO' database and CAS.

\section{Dovepress}

The manuscript management system is completely online and includes a very quick and fair peer-review system, which is all easy to use. Visit http://www.dovepress.com/testimonials.php to read real quotes from published authors. 